\title{
Isı Transferiyle Çalışan Anemometre Sistemleri
}

\author{
Burak Türüdü ${ }^{1 *}$ \\ 1*ARGE /ESITT Elektronik Sistemler İmalat ve Tic. Ltd.Şti, İstanbul, Türkiye (ORCID: 0000-0003-4571-5782), burakt@esit.com.tr
}

(1st International Conference on Applied Engineering and Natural Sciences ICAENS 2021, November 1-3, 2021)

(DOI: 10.31590/ejosat.1009169)

ATIF/REFERENCE: Türüdü, B. (2021). Isı Transferiyle Çalışan Anemometre Sistemleri. Avrupa Bilim ve Teknoloji Dergisi, (28), 614-617.

Öz

Rüzgarın yönünün ve hızının ölçülmesine birçok alanda ihtiyaç duyulmaktadır. Rüzgarın yönünü ve hızını ölçmek için kullanılan sistemlere anemometre adı verilmektedir. Anemometre sistemleri sivil ve askeri olmak üzere birçok alanda kullanılmaktadır. Sivil ve askeri alanlarda kullanılan birden fazla anemometre çeşidi bulunmaktadır. Anemometreler farklı ölçüm prensipleriyle çalışmaktadır. Kullanılacak olan anemometre kullanım alanının koşullarına göre seçilmektedir. Bu çalışmada 1sı transferi prensibiyle çalışan anemometre çeşitleri incelenmiştir. Isı transferi prensibiyle çalışan anemometrelerin devre yapıları, ölçüm sistemleri ve kullanılan malzemeler üzerine detaylı bir çalışma yapılmıştır. Isı transferiyle çalışan anemometreler karşılaştırılmıştır. Avantaj ve dezavantajları belirtilmiştir.

Anahtar Kelimeler: Anemometre, Rüzgar, Kızgın telli anemometre, Sabit voltajlı anemometre, Sabit sıcaklıklı anemometre

\section{Heat Transfer Anemometer Systems}

\begin{abstract}
Measuring the direction and speed of the wind is needed in many areas. Systems used to measure the direction and speed of the wind are called anemometers. Anemometer systems are used in many areas, including civilian and military. There are multiple types of anemometers used in civil and military fields. Anemometers work with different measurement principles. The anemometer to be used is selected according to the conditions of the usage area. In this study, types of anemometers working with the principle of heat transfer were examined. A detailed study has been made on the circuit structures, measurement systems and materials used of anemometers working with the heat transfer principle. Heat transfer anemometers were compared. Advantages and disadvantages are indicated.
\end{abstract}

Keywords: Anemometer, Wind Measurement, Wind, Hot wire anemometer, Constant voltage anemometer, Constant temperature anemometer

*Sorumlu Yazar: burakt@esit.com.tr 


\section{Giriş}

Günümüzde askeri alanlar başta olmak üzere pek çok farklı alanda rüzgarın hızının ve yönünün ölçülmesi gerekmektedir. Rüzgarın hızının ve yönünün ölçülmesi amacıyla kullanılan sistemlere anemometre adı verilmektedir. Günümüzde kullanılan birçok anemometre çeşidi bulunmaktadır. Bu çeşitlere örnek olarak kepçeli tip anemometre, ultrasonik anemometre, propeller anemometre ve kızgın telli anemometreyi verebiliriz. Kullanılan ortamdaki çevre şartlarına göre kullanılacak olan anemometre seçimi yapılmaktadır. Bu çalışmada kızgın telli anemometre çeşitleri detaylı olarak incelenecek ve karşılaştırılacaktır.

\subsection{Kepçe Tip Anemometre}

Rüzgar hızı ölçümü için kullanılan geleneksel bir yöntemdir. 19. Yüzyllın ortalarında T.R Robinson tarafından geliştirilmiştir. Bu tip anemometrede kepçe rotorunun bir dönüşü için geçen süreden rüzgarın hızı hesaplanmaktadır. [1]

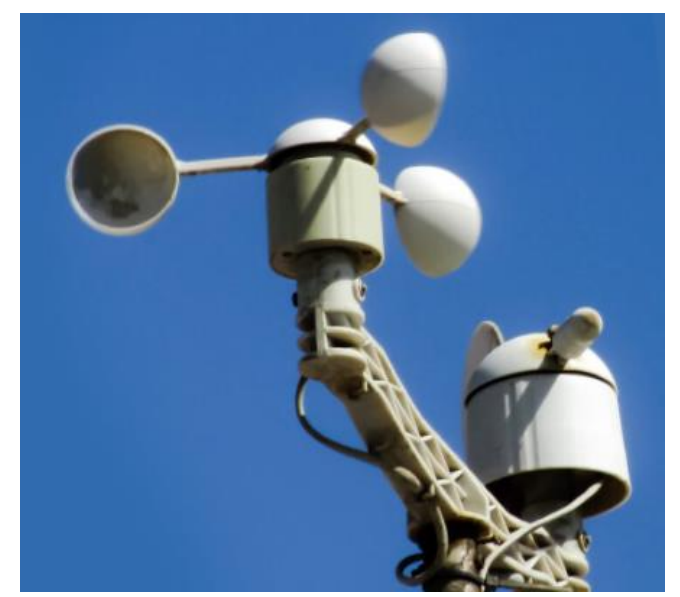

Şekil 1: Kepçe tip anemometre

\subsection{Ultrasonik Anemometre}

Rüzgar hızı ve yönünün ölçümü için kullanılan bir yöntemdir. Ultrasonik anemometre, her bir koldan yayılan ses dalgasının diğer kol tarafindan alınması sırasında geçen sürenin ölülmesi prensibi ile çalışmaktadır.[2]

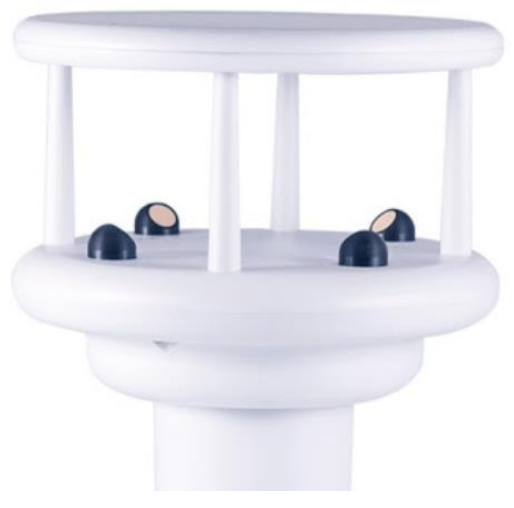

Şekil 2: Ultrasonik anemometre

\subsection{Propeller Anemometre}

Çalışma prensibi kepçe tip anemometre ile aynıdır. Montaj yönüne göre rüzgarın yataydaki ve dikeydeki hızını ölçebilmektedir.

\subsection{Kızgın Telli Anemometre}

Rüzgar hızı ve yönü ölçümü için kullanılan bir yöntemdir. Isı transferi prensibiyle ölçüm yapmaktadır. Sabit akımlı anemometre ve sabit sicaklıklı anemometre olmak üzere 2 ana altbaşlıkta incelenmektedir. Çalışmamızda kızgın telli anemometre çeşitleri birçok açıdan incelenecek ve karşılaştırılacaktır.

\section{Materyal ve Metot}

Kızgın telli anemometreler diğer anemometrelere göre daha stabil sistemlerdir. Çevresel koşulların anemometre üzerindeki etkisi diğer anemometrelere göre daha az olmaktadır. Kızgın telli anemometreler Askeri ve sivil birçok amaç için kullanılmaktadır. Kizgin telli anemometreler farkl1 materyallerden yapılabilmektedir ve farklı ölçüm teknikleriyle ölçüm yapılabilmektedir. Bu başlık altında kızgın telli anemometreler detaylı bir şekilde açıklanacaktır.

\subsection{Kızın Telli Anemometrelerin Kullanım Alanları}

Kızgın telli anemometrelerin kullanım alanları askeri ve sivil olmak üzere 2 alt başlıkta incelenebilir.

\subsubsection{Askeri kullanım alanlart}

Kızgın telli anemometreler askeri alanlarda yaygın bir şekilde kullanılmaktadır. Tank ve hava savunma sistemi gibi cihazlarda atış öncesi rüzgar yönünü ve hızını hesaba katarak yön düzeltmesi yapılmaktadır. Bu amaçla rüzgarın yön ve hızının tespit edilmesi için güvenilirliği ve çevresel koşullara dayanınıklılı̆g 1 nedeniyle kızgın telli anemometreler kullanılmaktadır.

\subsubsection{Sivil kullanım alanlart}

Kızgın telli anemometreler sivil alanda birçok farklı amaçla kulanılmaktadır. Personel güvenliği için yangınla mücadele, inşaatlar, limanlar ve diğer endüstriyel tesislerde kullanılmaktadır. Bunlara ek olarak rüzgar türbinleri, dağ geçitleri, yüksek köprüler gibi rüzgarın etkisinin olağan işleyişi bozma ihtimali olan yerlerde kullanılmaktadır.

\subsection{Kızgin telli anemometrelerde kullanılan probe malzemeleri}

Kızgın telli anemometrelerde 1sınarak rüzgarın ölçümünün yapılmasını sağlayan probda kullanılan malzemeler farklılık göstermektedir. Sensorde kullanılacak malzeme sağlamlık, lehimlenebilirlik, yüksek bir sıcaklık direnç katsayısına sahip olması gibi özelliklere göre seçilmektedir. Bu amaçla kullanılan malzemeler tungten, platin, platin-iridium alaşımı ve platin rodyum alaşımıdır. [3] 


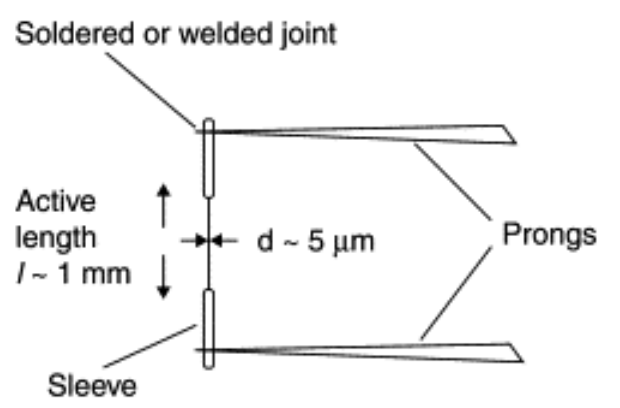

Şekil 3: Örnek prob yapısı

\begin{tabular}{|c|c|c|}
\hline Malzeme cinsi & $\begin{array}{c}\text { Maksimum } \\
\text { sicaklık }\left({ }^{\circ} \mathrm{C}\right)\end{array}$ & $\begin{array}{c}\text { S1caklık } \\
\text { Katsayıs1 } \\
\alpha(K-1)\end{array}$ \\
\hline Tunsten & 300 & 0.0047 \\
\hline Platin & 1800 & 0.0038 \\
\hline Platin-İridyum & 750 & 0.00085 \\
\hline Platin-rodyum & 1400 & 0.0016 \\
\hline
\end{tabular}

\subsubsection{Tungsten}

Tungsten teller sağlamdır ve yüksek sıcaklık direnç katsayısına sahiptir. Fakat lehimlenemezler ve kolay oksitlenirler. Bu sebeple problarda kullanım için çok fazla tercih edilmezler.[3]

\subsubsection{Platin}

Platin teller kolay oksitlenmezler ve sicaklık direnç katsayıları yüksektir. Yüksek sıcaklıklarda düşük mekanik mukavemete sahiptirler. Platin prob yapımında tercih edilen malzemelerin başında gelmektedir.[3]

\subsubsection{Platin-Iridyum}

Platin iridyum alaşımı yüksek sıcaklıklarda kararsız bir alaşımdır. Bu sebeple çok tercih edilmemektedir.[3]

\subsubsection{Platin}

Platin rodyum alaşımı tungsten ve platin arasında bir bölgededir. Oksitlenmeye karşı dirençlidir ve platinden daha fazla mekanik mukavemete sahiptir. Fakat sıcaklık direnç katsayısı düşüktür.[3]

\subsection{Kızgin telli anemometre teknikleri}

Kızgın telli anemometrelerde temel ölçüm tekniği sensor telinin enerji dengesi prensibine dayanır. Sensor üzerindeki gücün etkisiyle ısınır ve rüzgar etkisiyle soğur. Telin sıcaklık-direnç katsayısı yüksek olması nedeniyle tel direnci sıcaklığa paralel olarak belirgin bir değişim gösterir. Bu değişim üzerinden rüzgar hızı hesaplanır. Kızgın telli anemometreler rüzgar ölçümü yapmak için 2 temel ölçüm yöntemi kullanmaktadır. Bunlar sabit akıml anemometre ve sabit sicaklıklı anemometre olarak isimledirilmektedir. Bu bölümde bu iki anemometre çeşidi detaylı bir şekilde ele alınacaktır. [3][4]

\subsubsection{Sabit akımlı kıgın telli anemometre}

Sabit akımlı kızgın telli anemometrede hazırlanan elektronik devre sensor probu üzerine sabit akım sağlar. Sensordaki akımı sabit tutmak için sensore seri olarak büyük bir direnç bağlanır. $\mathrm{R} \gg>$ Rsensor(Rw) olduğunda akım pratikte Rsensor(Rw)'den bağımsız olarak alınabilir. Uygulamada Wheatstone köprüsü devresi kurulur. Bu devre sayesinde sabit akımla isıtılmış olan sensorun direnç değeri ölçülebilir. Sensor direnci değiştiğinden ve üzerindeki akım sabit olduğundan dolayı voltaj değişir. Değişen voltaj sayesinde rüzgar hızı hesaplanır. [3][4]

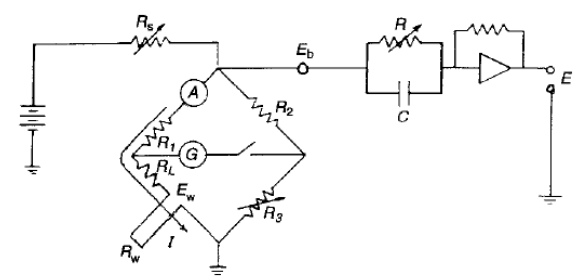

Şekil 4: Sabit akımlı kızgın telli anemometre devresi

\subsubsection{Sabit sicaklıklı klzgin telli anemometre}

Sabit sıcaklıklı kızgın telli anemometrede hazırlanan devre sensor sıcaklı̆ğının yani direncinin sabit tutulmasını sağlar. $\mathrm{Bu}$ sistemde de rüzgar hızını ölçmek için wheatstone köprüsü kullanılmaktadır. Wheatstone köprüsünde kollara belirli oranlarda dirençler bağlanılır. Sensorun denge durumu sabit tutulacak sıcaklıktadır. Probdan rüzgar geçmesi durumunda sensor soğur ve direnç düşer. Direnç düşümü nedeniyle wheatstone köprüsünde denge bozulur ve opamp çıkışı yükselir. Devre dengeye gelme amacıyla akımı yükseltir ve sıcaklığı aynı seviyeye getirir. Opamp çıkışı üzerinden rüzgar hızı hesaplanır. [3][4]

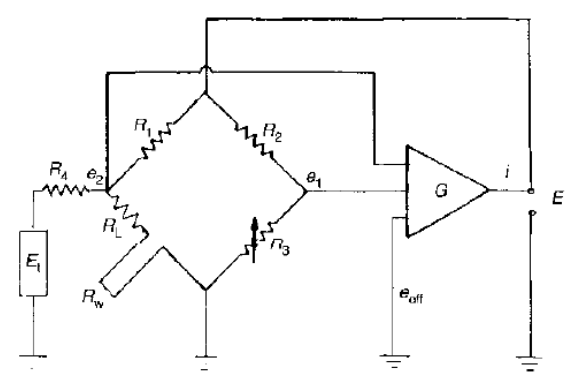

Şekil 5: Sabit akımlı kızgın telli anemometre devresi

\section{Araştırma Sonuçları ve Tartışma}

Kızgın telli anemometre çeşitleri, devre yapıları incelenmiştir. Ikisi arasındaki benzerlikler ve farklllıklara ait karşılaştırmalar sonucu avantaj ve dezavantajları belirlenmiştir. $\mathrm{Bu}$ bölümde kızgın telli anemometre çeşitlerinin avantaj ve dezavantajlarına yer verilmiştir. [4][5][6]

\subsection{Sabit akımlı kızgın telli anemometrenin avantaj ve dezavantajları}

Avantajları

- Yüksek frekans cevabı nedeniyle hız değişimlerine hızlı tepki vermektedir.

Dezavantajları 
- Kullanımı zordur.

- Devre çıkış değeri hızla birlikte düşer.

- Probun fazla isinma sebebiyle yanarak kullanılamaz hale gelme riski vardır.

\subsection{Sabit sıcaklıklı kızgın telli anemometrenin avantaj ve dezavantajları}

Avantajları

- Kullanımı kolaydır.

- Yüksek frekans cevabı nedeniyle hız değişimlerine hızlı tepki vermektedir.

- Gürültünün devre üzerindeki etkisi düşüktür.

- Standart haline getirilmiş ve daha yaygın kullanılan bir yapıya sahiptir.

- Sensorun hızı tüm rüzgar hızları için sabit tutulduğundan dolayı akış hızının ani değişimlerinde probun yanması engellenir.

- Çıkış geriliminin hız ile lineerleştirilmesi sağlanır.

Dezavantajları

- Kullanımı için gereken devre sabit akımlı kızıın telli anemometre devresine göre daha kompleks bir yapıya sahiptir.

\section{Sonuç}

Bu çalışmada anemometreler hakkında genel bilgiler verilmiş olup, kızgın telli anemometreler detaylı bir şekilde incelenmiştir. Devre yapılarından ve çalışma prensiplerinden detaylı olarak bahsedilmiş avantaj ve dezavantajları karşılaştırılmıştır.

\section{Teșekkür}

Bu çalışmada testlerde kullanılması gereken komponentleri, kızgın telli anemometre probları ve test ekipmanları için sağlanan maddi desteklerinden dolayı ESIT Elektonik Sistemler İmalat ve Tic. Ltd. Sti firması yönetim kurulu üyelerinden sayın Ferhat Tigrel ve Serhat Tigrel'e, teknik desteklerinden dolayı AR-GE departmanı müdürü sayın Berk Güldoğan'a teşekkürü bir borç bilirim.

\section{Kaynakça}

[1] Alvaro Ramos-Cenzano, Elena Lopez-Nunez, Daniel Alfonso-Corcuera, Mike Ogueta-Gutierrez, Santiago Pindado, 2021, On cup anemometer performance at high altitude above ground, Flow Measurement and Instrumentation 79101956

[2] Dongwoo Han, Sunghyun Kim, Sekwang Park, October 2008, Two-dimensional ultrasonic anemometer using the directivity angle of an ultrasonic sensor, Microelectronics Journal, Vol 39, Issue 10, S 1195-1199. DOI: 10.1016 / j 2008.01.090

[3] Giuseppe P.Russo, 2011, Aerodynamic Measurements, From physical Principles to Turnkey Instrumentation, Sayfa 67-98

[4] Dilek Funda KURTULUŞ, 2010, Experimental Aerodynamics(AR547-EN) ders notlar1, Ders 8, METU, https://ocw.metu.edu.tr/mod/resource/view.php?id=1133 (Erişim tarihi : 03.06.2021)

[5] M.A. Kegerise, E.F. Spina, 2000, A comparative study of constant-voltage and constant-temperature hot-wire anemometers, Part 1: The static response, Experimenents in fluids 29, Springer-Verlag, sayfa 154-164

[6] M.A. Kegerise, E.F. Spina, 2000, A comparative study of constant-voltage and constant-temperature hot-wire anemometers, Part 2: The dynamic response, Experimenents in fluids 29, Springer-Verlag, sayfa 165-177 